\title{
Semantic categorizations and encoding strategies
}

Stavros Skopeteas

\section{Introduction ${ }^{1}$}

Languages differ with respect to the lexicalization of the conceptual distinction between the region SUPERIOR \& CONTACT (cf. English on), i.e. in a place which is higher than the place occupied by the landmark and in contact to it, and the region SUPERIOR \& NON-CONTACT (cf. English above), i.e. in a place which is higher than the place occupied by the landmark and without contact to it. Both concepts are instances of the superordinate concept of SUPERIOR, i.e. the space that is in the positive domain of a vertical coordinate which originates at the landmark.

The typological variation concerning the encoding of these concepts contains: (a) languages that lexicalize the subordinate concepts, e.g. German and Russian; (b) languages that only lexicalize the superordinate concept, e.g. Korean and Yucatec Maya; (c) languages that lexicalize the superordinate concept and one of the subordinate concepts, e.g. Nanafwe; and (d) languages that lexicalize the superordinate concept in one paradigm of local relators and the subordinate concepts in another, e.g. Modern Greek.

Speakers of these representative languages have participated in a number of interactive games, in which either the superordinate or the subordinate concept of the taxonomic relation at issue was required in order to fulfill the game tasks. The collected results show that the diversity in semantic categorizations partially determines the encoding strategy used. In particular, languages differ in (a) the lexicalization pattern they choose in order to encode identical concepts, (b) the concept they choose in order to conceptualize identical situations, and (c) the semantic vs. pragmatic conveyance of the same concept.

\section{Preliminary remarks}

\subsection{Encoding taxonomical relations}

A classical problem in semantic categorization is the mismatch between languages providing different exponents with respect to a taxonomical relation: given a taxonomy of a superordinate concept $\mathrm{x}$ and some subordinate con- 
cepts $\mathrm{y}$ and $\mathrm{z}$, it is a usual situation that a language $\mathrm{L}_{1}$ lexicalizes $\mathrm{x}$ whereas some other language $\mathrm{L}_{2}$ lexicalizes $\mathrm{y}$ and $\mathrm{z}$.

The case study presented in this paper is concerned with the distinction between two spatial regions: the region of SUPERIOR \& CONTACT and the region of SUPERIOR \& NON-CONTACT (see definitions in Section 2.4.). English encodes this semantic distinction by the prepositions on and above. Setting aside the polysemy of these two prepositions, they both express location in the space in the positive domain of a positive coordinate originating at the landmark (SUPERIOR). Furthermore, the preposition on expresses location in a place that is in contact to the place occupied by the landmark, whereas the preposition above expresses location in a place that is not in contact to it. The superordinate concept in this case is the region of SUPERIOR, which only carries one feature and is not specified with respect to CONTACT/NON-CONTACT. The concepts SUPERIOR \& CONTACT and SUPERIOR \& NON-CONTACT are conceptually subordinated to the concept SUPERIOR, since their instances necessarily instantiate SUPERIOR as well. The relation among the subordinate concepts is one of conceptual incompatibility in terms of Schalley and Zaefferer (this vol.) since they are complementary.

From a cross-linguistic perspective, languages differ with respect to the encoding of this categorization: (a) the subordinate-encoding type includes languages that lexicalize the subordinate concepts SUPERIOR \& CONTACT and SUPERIOR \& NON-CONTACT (see Section 3.); (b) the superordinate-encoding type includes languages that do not make this distinction and provide only one element lexicalizing the concept of SUPERIOR (see Section 4.); and (c) the mixed type includes languages that lexicalize the superordinate concept of SUPERIOR and one of the subordinate concepts (see Section 5.). Furthermore, some languages may display internal variation as regards this typology, thus belonging to different types with respect to different constructions. This encoding type is treated as a split system (see Section 6.).

The purpose of this paper is to explore the impact of the typological diversity in semantic classifications upon the performance of communicative tasks. By means of an interactive game, outlined in Section 1.2., speakers of the above language types are exposed to identical discourse situations. The data gained on the basis of this experiment differ with respect to the syntactic, semantic, and pragmatic means that speakers of different languages use to perform identical tasks. 


\subsection{Experimental setting}

The empirical data was gained through a series of interactive games that were designed to collect data on spatial descriptions concerning the distinction of CONTACT vs. NON-CONTACT in the domain of SUPERIOR. The games are performed by two consultants, one taking the role of the director and one taking the role of the matcher. The director holds a series of picture pairs in randomized order. In each pair one picture is highlighted. The matcher is given the same series in identical order, but his series lacks highlighting. The instruction to the director has been the following: "Describe to your partner the highlighted picture in each pair". The matcher has been instructed to listen to his partner and to point to the highlighted picture. The pairs used in the games are presented in Table 1.

Table 1. Experimental conditions

\begin{tabular}{|c|c|c|}
\hline & highlighted pictures & background pictures \\
\hline Condition 1 & SUPERIOR \& CONTACT & $\begin{array}{l}\text { SUPERIOR \& NON-CON- } \\
\text { TACT }\end{array}$ \\
\hline Game 1 & ting on the elephant & a bird flying above an elephant \\
\hline Game 2 & $\begin{array}{l}\text { a hand holding a candle on a ta- } \\
\text { ble }\end{array}$ & $\begin{array}{l}\text { a hand holding a candle above } \\
\text { a table }\end{array}$ \\
\hline Game 3 & a pot hanging on the fire & a pot hanging above the fire \\
\hline Condition 2 & $\begin{array}{l}\text { SUPERIOR \& NON-CON- } \\
\text { TACT }\end{array}$ & SUPERIOR \& CONTACT \\
\hline Game 4 & a bird flying above an elephant & on the elephant \\
\hline Game 5 & $\begin{array}{l}\text { a hand holding a candle above } \\
\text { a table }\end{array}$ & $\begin{array}{l}\text { a hand holding a candle on a ta- } \\
\text { ble }\end{array}$ \\
\hline Game 6 & a pot hanging above the fire & a pot hanging on the fire \\
\hline Condition 3 & SUPERIOR & NON-SUPERIOR \\
\hline Game 7 & a bird flying above an elephant & a bird flying under an elephant \\
\hline Game 8 & $\begin{array}{l}\text { a hand holding a candle above } \\
\text { a table }\end{array}$ & $\begin{array}{l}\text { a hand holding a candle at the } \\
\text { left side of a table }\end{array}$ \\
\hline Game 9 & a pot hanging on the fire & $\begin{array}{l}\text { a pot hanging at the right side } \\
\text { of the fire }\end{array}$ \\
\hline Game 10 & a pot hanging above the fire & $\begin{array}{l}\text { a pot hanging at the right side } \\
\text { of the fire }\end{array}$ \\
\hline Condition $4^{2}$ & $\begin{array}{l}\text { SUPERIOR \& NON-CON- } \\
\text { TACT }\end{array}$ & NON-SUPERIOR \\
\hline Game 11 & $\begin{array}{l}\text { a bird sitting on a tree branch } \\
\text { exactly above an elephant }\end{array}$ & $\begin{array}{l}\text { a bird sitting on a tree branch } \\
\text { not being above the elephant }\end{array}$ \\
\hline
\end{tabular}




\begin{tabular}{l|ll}
\hline Game 12 & $\begin{array}{l}\text { a hand holding a candle on a } \\
\text { stack of books that are on a ta- } \\
\text { ble }\end{array}$ & $\begin{array}{l}\text { a hand holding a candle at the } \\
\text { are on a table }\end{array}$ \\
a pot being on a table exactly & $\begin{array}{l}\text { a pot being on a table not above } \\
\text { above a fire which is under- } \\
\text { neath the table }\end{array}$ & $\begin{array}{l}\text { the fire which is underneath the } \\
\text { table }\end{array}$ \\
\hline
\end{tabular}

There are some consequences of the selected methodology that have to be mentioned in order to delimit the scope of the resulting generalizations. First of all, elicitation through pre-constructed discourse situations does not render naturalistic data about human communication. Speakers of different cultures are exposed to identical discourse situations and thus perform identical tasks, but it is possible that the situations compared do not occur with identical importance and frequency in natural communication of different interacting communities. However, the exploration of cultural diversity is beyond the scope of the methodology of this paper. Second, the games are designed for situations that differ with respect to the distinction between CONTACT/NON-CONTACT between a localized object and a landmark. Consequently, the data gained supplies generalizations about only one aspect of the meaning of the spatial relators used in this context. Further distinctions in the domain of SUPERIOR that possibly interact with the distinction CONTACT/NON-CONTACT may not be accounted for through these experimental items. ${ }^{3}$ Furthermore, the descriptions gained through this experimental setting are induced through the contrast between a highlighted situation and a background situation. The collected descriptions would be not necessarily the same if the highlighted pictures were presented in isolation and hence the results do not allow for generalizations about the encoding of the highlighted situations without contrast.

\subsection{Language sample}

Speakers of representative languages for the types introduced in Section 2.1. have participated in the production experiment. The representative languages include: (a) two languages that encode the subordinate concepts: German and Russian; (b) two languages that encode the superordinate concept: Korean and Yucatec Maya; (c) a language representing the mixed systems, namely Nanafwe (dialect of Baole; Kwa: Ivory Coast), which encodes the superordinate concept of SUPERIOR and the subordinate concept of SUPERIOR 
\& NON-CONTACT; and (d) a language providing a constructional split, namely Modern Greek, that belongs to the subordinate-encoding type as regards the prepositional paradigm and to the superordinate-encoding type as regards the adverbial paradigm.

\subsection{Semantic representations}

The local situations of the experiment and the semantics of the collected expressions are represented in predicate logic in terms of Wunderlich and Herweg (1991). The localization of an entity is treated as a predicate with two arguments: the localized object $\mathrm{x}$ and the place it occupies in space. This place is part of the space defined by a region $u_{j}$ of a landmark $y$.

$$
\lambda \mathrm{x} \lambda \mathrm{y} \operatorname{LOC}\left(\mathrm{x}, \mathrm{u}_{\mathrm{j}}(\mathrm{y})\right)
$$

(see Wunderlich and Herweg 1991: 772)

The spatial region termed as SUPERIOR contains the space in the positive domain of the vertical lines that fall within the outline of the landmark $y$. The semantics of a local relator which encodes the superordinate concept of SUPERIOR and is underspecified for CONTACT/NON-CONTACT, as for instance the relational noun šinì in Mixtec, is given in (2):

$$
\begin{aligned}
& \text { šini: } \\
& \lambda \mathrm{x} \lambda \mathrm{y} \operatorname{LOC}(\mathrm{x}, \operatorname{SUPERIOR}(\mathrm{y}))
\end{aligned}
$$

The subordinate concepts combine the concept of SUPERIOR with the concepts of CONTACT/NON-CONTACT. It should be mentioned that the concept of CONTACT does not necessarily imply physical contact between the localized object and the landmark (see Klein 1991:96; Brala this vol.). The classical example is that the sentence the glass is on the table is true, even if a tablecloth is on the table and hence intervenes between the surface of the table and the glass. Following Klein (1991), we assume that the place occupied by the table is conceptualized as contiguous to the place occupied by the glass, insofar the place occupied by the tablecloth is not relevant enough to be chosen for landmark.

The concept of CONTACT will be treated in the context of our experiment as a spatial region and not as a predicate independent from the localizing function (see alternative representations in Wunderlich and Herweg 
1991: 778). In the experimental stimuli, the contrasted pictures differ with respect to the localization of the one entity. This contrast induces expressions that identify a certain search domain in the space, in which the hearer should find the localized object. In this sense, CONTACT is relevant for this discourse task only as a spatial region. Defined as such, the concept of CONTACT is a part of the space in proximity of the landmark $y$, termed as $\operatorname{EXT}(\mathrm{y})$. Within $\operatorname{EXT}(\mathrm{y})$, the part specified by the region of CONTACT is the space in which the place occupied by a localized object $\mathrm{x}$ and the place occupied by y are (conceptually and not necessarily physically) contiguous. This region will be represented as $\operatorname{EXT}^{\mathrm{C}}(\mathrm{y})$ following Wunderlich and Herweg (1991: 778) and will be referred in the plain text simply as CONTACT. The representation of the English prepositions on and above in (3) illustrates the semantics of local relators that encode the subordinate concepts:

on:

$$
\lambda \mathrm{x} \lambda \mathrm{y} \operatorname{LOC}\left(\mathrm{x},\left[\operatorname{SUPERIOR}(\mathrm{y}) \& \operatorname{EXT}^{\mathrm{C}}(\mathrm{y})\right]\right)
$$

$$
\begin{aligned}
& \text { above: } \\
& \lambda \mathrm{x} \lambda \mathrm{y} \operatorname{LOC}\left(\mathrm{x},\left[\operatorname{SUPERIOR}(\mathrm{y}) \& \neg \operatorname{EXT}^{\mathrm{C}}(\mathrm{y})\right]\right)
\end{aligned}
$$

As already mentioned in Section 2.2., the semantic properties which are inspected through our experiment are induced through the contrast of situations which involve the concepts of SUPERIOR and CONTACT. It has been shown that spatial prepositions in different languages usually contain further semantic properties that restrict their use in identifying search domains, and notably functional properties concerning the relation between the localized object and the landmark (see Aurnague and Vieu 1993:419-422). ${ }^{4}$ Semantic properties, beyond the concepts of SUPERIOR and CONTACT, are not accounted for through the current experimental design. In this sense, the semantic representations in this paper should be treated as partial representations containing only the variables which are experimentally manipulated.

The semantic representations of the local relators in the object languages will be compared with the language-independent conceptual structure, which is assumed by the experimental manipulation. Since the aim of this paper is to enable the comparison between language-independent discourse situations and language specific expressions, the representations of the conceptual structure will have the same formal elements as the representations of language-specific semantics.

We assume that the presentation of two pictures with two identical entities establishes the existence of two entities in the mental model of the in- 
formant. The design of situations forces the choice of a localized object and a landmark through a twofold asymmetry of the involved entities. In terms of salience, all pictures present pairs of asymmetrical entities (bird/elephant, candle/table, pot/fire), whereby the entity which is located in a higher location in the picture is more salient (i.e. smaller and more movable) than the entity which is located in a lower location. In terms of information structure, the intended landmark occupies a given place in both pictures and the intended localized object occupies different places in the highlighted picture and the background one. These asymmetries induce descriptions in which the landmark is the less salient entity occupying a given location, i.e. the collected results only contain descriptions of the kind the candle is under the table and not description of the kind the table is under the candle. Since this asymmetry is maintained experimentally constant and since it uniformly induces the same role choice in all languages, it will be part of the language-independent representation of the discourse situation, which is illustratively presented for Condition 2 in (5). This representation contains the localization presented in the highlighted picture in the second line and the localization presented in the background picture in the next line.

$$
\begin{array}{ll}
\text { Condition 2: } & \exists \mathrm{x} \exists \mathrm{y} \\
& \\
\text { highlighted picture: } & {\left[\operatorname{LOC}\left(\mathrm{x},\left[\operatorname{SUPERIOR}(\mathrm{y}) \& \neg \operatorname{EXT}^{\mathrm{C}}(\mathrm{y})\right]\right) \&\right.} \\
\text { background picture: } & \left.\neg \operatorname{LOC}\left(\mathrm{x},\left[\operatorname{SUPERIOR}(\mathrm{y}) \& \operatorname{EXT}^{\mathrm{C}}(\mathrm{y})\right]\right)\right]
\end{array}
$$

\section{Subordinate encoding languages}

Languages like German and Russian encode the subordinate concepts and not the superordinate one - at least by means of prepositions as illustrated in (6) for German.

\section{(6) German}

$$
\begin{array}{ll}
\text { superordinate (SUPERIOR) } & \rightarrow- \\
\text { subordinate (SUPERIOR \& EXT }{ }^{\mathrm{C}} \text { ) } & \rightarrow \text { auf } \\
\text { subordinate (SUPERIOR \& } \neg \mathrm{EXT}^{\mathrm{C}} \text { ) } & \rightarrow \text { über }
\end{array}
$$

Speakers of this language type include the concept of CONTACT/NONCONTACT in their descriptions, irrespective of its relevance for the discourse situation. Thus, German speakers use expressions like (7) both for the discourse situation of Game 6, whereby 'the pot above the fire' is contrasted 
to 'the pot on the fire', as well as the discourse situation of Game 10, in which the concept of NON-CONTACT is not needed for the task, since both pictures display 'a pot above the fire'. The same holds for the Russian expression in $(8)^{5}$ that applies to Game 4 and to Game 7 as well.

Der Topf hängt über dem Feuer.

'The pot hangs above the fire.' (Games $6 \& 10$ )

(8)

ptíca nad slonóm.

bird:NOM.SG.F above elephant:INSTR.SG.M

'A bird is above an elephant.' (Games 4 \& 7)

The encoding strategy of this language type is represented in (9)-(10). The discourse situation in (9) represents the case in which NON-CONTACT is the crucial concept for the identification of the highlighted picture. In the discourse situation in (10) the concept of NON-CONTACT is not relevant, since the highlighted picture may be successfully identified through the concept of SUPERIOR. In both cases, languages of the subordinate-encoding type use an expression that includes the concept of NON-CONTACT.

(9) Games 4 and 6:

$$
\begin{aligned}
& \text { Games } 4 \text { and 6: } \quad \exists \mathrm{x} \exists \mathrm{y} \\
& \text { highlighted picture: } \quad\left[\operatorname{LOC}\left(\mathrm{x},\left[\operatorname{SUPERIOR}(\mathrm{y}) \& \neg \operatorname{EXT}^{\mathrm{C}}(\mathrm{y})\right]\right) \&\right. \\
& \text { background picture: } \left.\neg \operatorname{LOC}\left(\mathrm{x},\left[\operatorname{SUPERIOR}(\mathrm{y}) \& \operatorname{EXT}^{\mathrm{C}}(\mathrm{y})\right]\right)\right] \\
& \text { local relator (subordinate encoding languages): } \\
& \lambda \mathrm{x} \lambda \mathrm{y} \operatorname{LOC}\left(\mathrm{x},\left[\operatorname{SUPERIOR}(\mathrm{y}) \& \neg \mathrm{EXT}^{\mathrm{C}}(\mathrm{y})\right]\right)
\end{aligned}
$$

(10) Games 7 and 10:

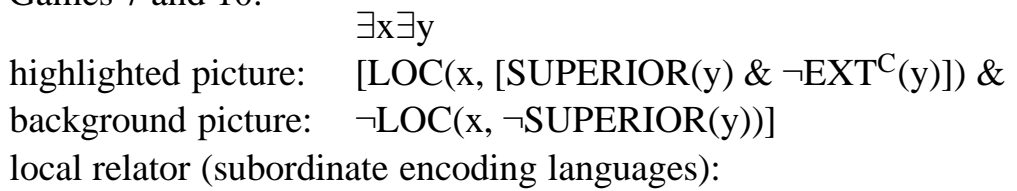$$
\lambda \mathrm{x} \lambda \mathrm{y} \operatorname{LOC}\left(\mathrm{x},\left[\operatorname{SUPERIOR}(\mathrm{y}) \& \neg \operatorname{EXT}^{\mathrm{C}}(\mathrm{y})\right]\right)
$$

\section{Superordinate encoding languages}

The second language type includes languages that encode the superordinate but not the subordinate concepts. This pattern occurs in Mixtec as shown in (11). The same relational noun šini occurs in examples that imply CON- 
TACT to the landmark, e.g. 'a person on the top of the tree' and in examples that exclude CONTACT, e.g. 'a bird flying above the tree' (see Macaulay 1996: 173, 179).

(11) Mixtec, Oto-Manguean (Macaulay 1996: 173)

$\begin{array}{ll}\text { superordinate (SUPERIOR) } & \rightarrow \text { šinì } \\ \text { subordinate (SUPERIOR \& CONTACT) } & \rightarrow- \\ \text { subordinate (SUPERIOR \& } \neg \text { CONTACT) } & \rightarrow-\end{array}$

The language type exemplified in (11) is very widespread: it occurs in native American languages, like Mixtec, Yucatec Maya (cf. (13)-(14)), and Imbabura Quechua (Cole 1985: 122-123), in East Asian languages like Japanese (see Section 4.2.1.) and Korean (cf. (12)), in Altaic languages like Turkish (Kornfilt 1997: 246-247), in Niger-Kongo languages like Koromfe (Rennison 1997: 175-178).

\subsection{Discourse situations profiling the superordinate concept}

The expression of CONTACT/NON-CONTACT in these languages mainly depends on the relevance of this concept for the discourse situation, i.e. speakers disregard this information if it is not relevant for the task. This is illustrated for Korean in (12). In both Games 9 and 10, Korean speakers use the same expression to identify the highlighted picture, although in the first, the pot is hanging with contact to the fire and in the latter it is hanging without contact to it. In both Games, the background picture shows a pot that is hanging not directly above the fire. The description in (12) only expresses the concept of SUPERIOR.

$$
\begin{aligned}
& \text { suphwu-ka pul uy-ey iss-ta } \\
& \text { soup-NOM fire on/above-LOC be-DECL } \\
& \text { 'The soup is on/above the fire.' (Games } 9 \& 10 \text { ) }
\end{aligned}
$$

The same pattern occurs in Yucatec Maya: both (13) and (14) convey the highlighted location by means of the preposition yook'ol 'on/above', although sentence (13) has been produced in Game 9 which involves contact to the fire and (14) in Game 10 which does not. 
10 Stavros Skopeteas

(13) te'l-a' hun p'éel ch'óoy yàan ti' le k'áak'-o', yóok'ol. there-D1 one CL.INAN bucket EXIST LOC DEF fire-D2 on/above 'There is a bucket at the fire, on/above.' (Game 9)

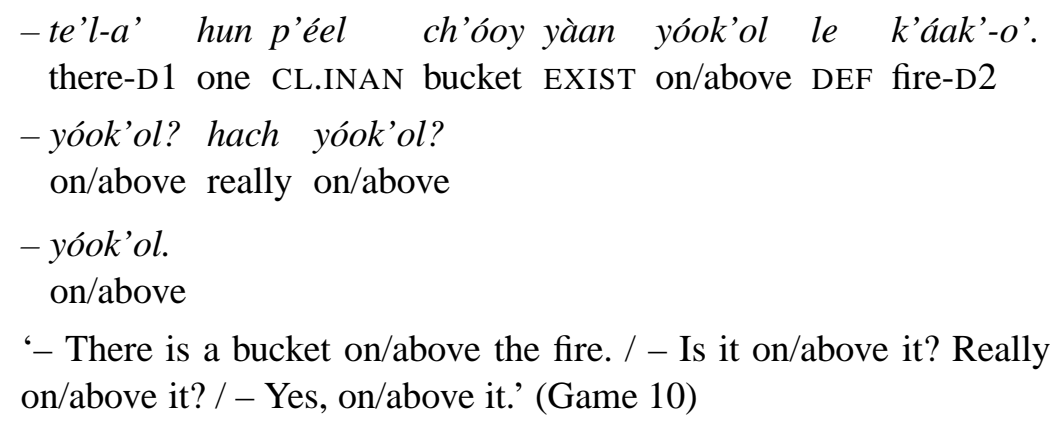

'- There is a bucket on/above the fire. / - Is it on/above it? Really on/above it? / - Yes, on/above it.' (Game 10)

In these examples, the discourse situation profiles the superordinate concept. (15) represents the encoding strategy of superordinate-encoding languages in situations in which CONTACT/NON-CONTACT is not relevant for the communicative task; this feature is simply ignored (compare (10)).

(15) Game 10:

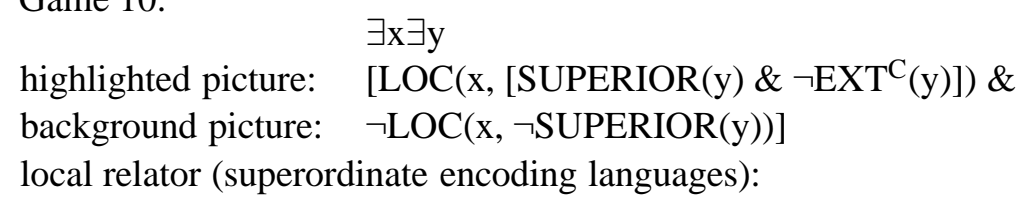

$$
\lambda \mathrm{x} \lambda \mathrm{y} \operatorname{LOC}(\mathrm{x}, \operatorname{SUPERIOR}(\mathrm{y}))
$$

(16) Game 9:

$$
\exists x \exists y
$$

highlighted picture: $\quad\left[\operatorname{LOC}\left(\mathrm{x},\left[\operatorname{SUPERIOR}(\mathrm{y}) \& \operatorname{EXT}^{\mathrm{C}}(\mathrm{y})\right]\right) \&\right.$ background picture: $\neg$ LOC $(\mathrm{x}, \neg \operatorname{SUPERIOR}(\mathrm{y}))]$

local relator (superordinate encoding languages):

$$
\lambda \mathrm{x} \lambda \mathrm{y} \operatorname{LOC}(\mathrm{x}, \operatorname{SUPERIOR}(\mathrm{y}))
$$

4.2. Discourse situations profiling the subordinate concepts

The crucial question with respect to this language type is how speakers deal with discourse situations that profile subordinate concepts. Languages of this type employ different strategies to resolve this task: (a) speakers encode similar semantic representations by using different lexi- 
calization patterns, especially by using verbs to encode the concepts of CONTACT/NON-CONTACT (see Section 4.2.1.) rather than adpositions; (b) speakers encode different semantic representations to perform identical discourse tasks, e.g. expressing absolute location in the vertical axis instead of CONTACT/NON-CONTACT (see Section 4.2.2.); or (c) speakers make use of inferential patterns instead of semantic representations to resolve the task, e.g. inferring CONTACT/NON-CONTACT from the information about MANNER of motion or POSTURE of the localized object (see Section 4.2.3.).

\subsubsection{Diversity in lexicalization pattern}

The first case of language diversity to be discussed here concerns the use of different lexicalization patterns. ${ }^{6}$ As a case of difference in means of lexicalization, recall Example (12) from Korean. Whenever the concepts of CONTACT/NON-CONTACT are not relevant for the discourse situation, they are not expressed, as it is shown in the representation in (15). In Game 6, however, the discourse situation requires the concept of NON-CONTACT, since the highlighted picture differs from the background picture only with respect to this concept. Korean speakers resolve this task by using a converb with the meaning 'disjoint' (cf. (17)). The same converb appears also in other Games that require the concept of NON-CONTACT (cf. Game 5 in (18)).

$$
\begin{array}{llll}
\text { yangtongi-ka } & \text { pul uy-ey } & \text { ttele-ci-e } & \text { iss-ta } \\
\text { bucket-NOM fire on/above-LOC } & \text { disjoin-PASS-INF } & \text { be-DECL }
\end{array}
$$

'the bucket is above the fire (lit. is disjoined in the on/above domain of the fire)' (Game 6)

$$
\text { cho-ka teyibl uy-ey ttele-ci-e iss-ta }
$$

candle-NOM table on/above-LOC disjoin-PASS-INF be-DECL

'the candle is above the table (lit. is disjoined in the on/above domain of the table)' (Game 5)

Thus, while German lexicalizes both SUPERIOR and NON-CONTACT through a single adposition (cf. (6)), Korean lexicalizes SUPERIOR through an adposition and NON-CONTACT through a verb (see (19)). Not taking into account the difference in obligatory/optional encoding of the subordinate concept, the Korean example in (17) and the German example in (7) show two different lexicalization patterns for the same information for Game 6. 
(19)

$$
\begin{array}{ll}
\text { Korean } & \\
\text { superordinate (SUPERIOR) } & \rightarrow \text { uy-ey } \\
\text { subordinate (SUPERIOR \& } \neg \text { CONTACT) } & \rightarrow \text { uy-ey ttele-ci-e }
\end{array}
$$

In the examples under consideration, the superordinate-encoding language makes use of an additional element, namely a verb form, in order to provide additional information about NON-CONTACT. An interesting question is if motion verbs in a language lacking the concepts of CONTACT/NONCONTACT in the adpositional paradigm are specified with respect to these concepts. This would support the idea of functional complementarity of verbs and adpositions in the lexicalization of spatial relations. Without allowing a generalization concerning all motion verbs, there are such instances of complementarity as it will be exemplified by the verb 'fly' in Korean and English. English fly does not imply necessarily NON-CONTACT to the landmark encoded through the adjoined PP. Thus, it is possible to use the verb fly with either on or above as in (20a-b).

a. Aladdin is flying on the carpet.

b. Aladdin is flying above the carpet.

Contrary to English, the Korean verb for the concept FLY includes the concept of NON-CONTACT. Consider Example (21): the Korean postposition $u y$ 'on/above' only encodes the concept of SUPERIOR. The compositional interpretation of a verb encoding the concept FLY with an adposition encoding SUPERIOR is expected to be ambiguous between the meanings illustrated by the English Examples (20a-b). However, it is not ambiguous in Korean. Example (21) can only mean 'Aladin is flying above the carpet'. Since the postposition does not contain the concept of NON-CONTACT, it should be carried by the verb (notice that the verb in this construction governs the Korean postposition with an accusative suffix). The meaning 'flies on the carpet' is only possible with the use of an additional verb that contains the concept of CONTACT and is a converbal dependent of the matrix verb (see (22)).

$$
\begin{aligned}
& \text { aladin-un yangtanca uy-lul nal-n-ta. } \\
& \text { Aladin-TOP carpet on/above-ACC fly-above-PRES-DECL } \\
& \text { 'Aladin is flying above the carpet.' } \\
& \text { *'Aladin is flying on the carpet.' }
\end{aligned}
$$




$$
\begin{aligned}
& \text { aladin-un yangtanca-lul tha-ko nal-n-ta. } \\
& \text { Aladin-TOP carpet-ACC get.on-CON fly.above-PRES-DECL } \\
& \text { 'Aladin is flying on the carpet (lit. by being on the carpet).' }
\end{aligned}
$$

To that effect, Korean descriptions involving the verb 'fly' (cf. (23)) contain the concept of NON-CONTACT and are semantically equivalent to corresponding descriptions in subordinate-encoding languages (cf. (24)), differing only with respect to the distribution of features in the syntactic constituents.

$$
\text { say-ka khokkili uy-lul nal-n-ta. }
$$

bird-NOM elephant on/above-ACC fly.above-PRES-DECL

'The bird is flying above the elephant.' (Game 4)

\section{Der Vogel fliegt über dem Elefanten.}

'The bird is flying above the elephant.' (Game 4)

\subsubsection{Diversity in semantic structure}

In the examples considered so far, languages select a concept included in the discourse situation either obligatorily (subordinate encoding languages) or only if relevant (superordinate encoding languages). Another instance of language diversity in our corpus concerns cases in which languages lexicalize different concepts in order to fulfill the same task. A difference in lexicalization pattern may occur as accompanying property to this deviation, but the relevant issue is the difference in semantic structure.

Consider Games 3 and 6 that oppose 'a pot on the fire' to 'a pot above the fire', respectively highlighting the first and the latter situation. There are at least two possible ways to express the location of the pot: The first way is to express the relative location of the bucket with respect to the landmark 'fire'. Languages of the subordinate-encoding type do this by means of 'on' and 'above'. An alternative way is to express the location in terms of 'high' and 'low', hence in absolute terms by encoding position in the vertical axis as an absolute frame of reference originating from the ground. ${ }^{7}$ This solution occurs in the data from Yucatec Maya and is exemplified in (25) for CONTACT and in (26) for NON-CONTACT. In both examples the director of the game has given an ambiguous description using the preposition yookol 'on/above'. The matcher asks for clarification using the adverbs káabal 'low' (etym. 'ground') and ka'nal 'high' (etym. 'sky'). 
14 Stavros Skopeteas

$$
\text { -te'l-a' hun-p'éel ch'óoy yàan yóok'ol le k'áak'-o'. }
$$
there-D1 one-CL.INAN bucket exist on/above DEF fire-D2

- kàabal wáah ka'nal? low or high

- kàabal. low

'- There is a bucket on/above the fire./ - Low or high?/ - Low.' (Game 3)

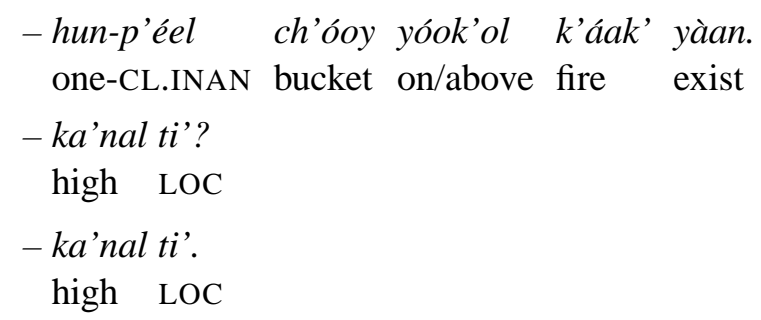

'- There is a bucket on/above a fire. / - High? / - Yes, high.' (Game 6)

The encoding strategy used in Game 6 is represented in (27) (compare subordinate encoding languages in (9)). The adverb ka'nal 'high' is a oneplace function with a internal argument for the zero point of the axial system which is not lexicalized in the utterance. ${ }^{8}$ This is by default the ground, but it may also be another reference object retrieved from the context.

Game 6:

$\begin{array}{ll} & \exists \mathrm{x} \exists \mathrm{y} \\ \text { highlighted picture: } & {\left[\mathrm{LOC}\left(\mathrm{x},\left[\operatorname{SUPERIOR}(\mathrm{y}) \& \neg \operatorname{EXT}^{\mathrm{C}}(\mathrm{y})\right]\right) \&\right.}\end{array}$ background picture: $\left.\quad \neg \operatorname{LOC}\left(\mathrm{x},\left[\operatorname{SUPERIOR}(\mathrm{y}) \& \operatorname{EXT}^{\mathrm{C}}(\mathrm{y})\right]\right)\right]$ semantics of Yucatec local relator:

$$
\lambda x \operatorname{LOC}(\mathrm{x}, \operatorname{HIGH}(\mathrm{y}))
$$

\subsubsection{Pragmatic inferences}

A further varying parameter in the discourse situations under consideration concerns the different manners of motion and the different postures of the localized objects. Several manners of motion or postures often offer the basis for pragmatic inferences of the concepts of CONTACT/NON-CONTACT. For example, the fact that a localized object is sitting on/above a landmark 
implies that there is contact between localized object and landmark, or the fact that the localized object is flying on/above a landmark implies that there is no contact to the landmark. In contrast to manner/posture verbs that entail the concept of CONTACT such as the Korean verb 'fly' (see Section 4.2.1.), the current section deals with verbs that do not entail this concept.

Posture verbs in several languages may be used without specification of the concept of CONTACT by the locative adjunct although this concept is part of the situation (cf. Enfield 2002:32-33; Newman 2002: 5). In Lao, utterances with the verb 'to sit' and the landmark 'chair' without any overt marker of either SUPERIOR or CONTACT give rise to an interpretation that includes both concepts as illustrated in (20a). Nevertheless, this inference is possible insofar this localization is a default situation in the common ground of the interlocutors, and it is cancelable by the change of the entities involved (cf. (20b)).

$$
\begin{aligned}
& \text { a. man2 nang1 tang1 } \\
& 3 \text { sit chair } \\
& \text { 'He sat/is sitting (on a) chair.' (cf. Enfield 2002: 32) } \\
& \text { b. man2 nang1 toq } 2 \\
& 3 \text { sit table } \\
& \text { 'He sat/is sitting (at a) table.' (cf. Enfield 2002: 32) }
\end{aligned}
$$

In our experimental data, languages that do not encode the subordinate concepts, use sometimes pragmatic inferences on the basis of the encoded manners or postures. The positional verb 'squat' in Yucatec Maya is used for the posture of the bird on the elephant (Game 1), and also for the posture of the candle on the table (Game 2; see (29)). In both discourse situations, the concept of CONTACT is not encoded through the preposition yóokol 'on/above' although it is the identifying property of the highlighted picture.

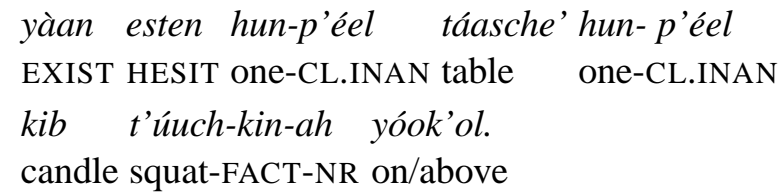

'There is a table, a candle is put on/above it in a squatting position.' (Game 2)

The description in (29) has been successfully accepted by the matcher of the game, who identified the target situation which involves the concept of 


\section{Stavros Skopeteas}

CONTACT. Both in the highlighted picture as well as in the background picture the candle is presented as being hold by a hand in order to eliminate the difference in posture which adds a further difference in the situations. Nevertheless the Yucatec speaker has imposed postural information in terms of squatting in order to introduce the concept of CONTACT.

The question is if the verb t'úuch- 'squat' includes the concept of CONTACT or if this is pragmatically inferred as in the Lao Example (28a). Condition 5 in the experimental material (see Table 1) has been designed to test the defeasibility of such inferences. In Game 12, the same posture occurs but the candle is not located immediately on the table but it is squatting on a stack of books that are on the table. The informant has been asked if the utterance in (30) is true for the situation in Game 12 and she judged it as acceptable.

$$
\text { yàan hun-p'éel kib t'úuchukbal yóok'ol le táasche'-o' }
$$
EXIST one-CL.INAN candle squat:POS on/above DEF table-D2

'There is a candle put on/above the table in a squatting position.' (Game 12)

Consequently the relation between the concept of CONTACT is not a semantic feature of the verb t'úuch- 'squat' but a defeasible inference as represented in (31). The pragmatic inference originates in the conjunction of the posture SQUAT and the concept of SUPERIOR: 'if $\mathrm{x}$ is squatting somewhere in the vertical axis of $y$, it is highly probable that it squats on $y$ because of gravity'.

$$
\begin{array}{ll}
\text { Game 2: } & \exists \mathrm{x} \exists \mathrm{y} \\
& \\
\text { highlighted picture: } & {\left[\operatorname{LOC}\left(\mathrm{x},\left[\operatorname{SUPERIOR}(\mathrm{y}) \& \operatorname{EXT}^{\mathrm{C}}(\mathrm{y})\right]\right) \&\right.} \\
\text { background picture: } & \left.\neg \operatorname{LOC}\left(\mathrm{x},\left[\operatorname{SUPERIOR}(\mathrm{y}) \& \neg \operatorname{EXT}^{\mathrm{C}}(\mathrm{y})\right]\right)\right] \\
\text { semantics of Yucatec } & t^{\prime} \text { úuch-kin-ah yóok'ol: } \\
& \lambda \mathrm{x} \lambda \mathrm{y}[\operatorname{LOC}(\mathrm{x}, \operatorname{SUPERIOR}(\mathrm{y})) \& \operatorname{SQUAT}(\mathrm{x})] \\
\text { pragmatic inference: } & \\
& {\left[\operatorname{LOC}\left(\mathrm{x}, \operatorname{SUPERIOR}^{\mathrm{S}}(\mathrm{y})\right) \& \operatorname{SQUAT}(\mathrm{x})\right]} \\
& +>\operatorname{LOC}\left(\mathrm{x}, \operatorname{EXT}^{\mathrm{C}}(\mathrm{y})\right)
\end{array}
$$

\section{Mixed systems}

Languages with "mixed systems" combine the encoding of the superordinate with the encoding of one of the subordinate concepts. Babungo (Niger- 
Kongo) employs a preposition, which encodes the superordinate concept, and another one, which encodes the one subordinate concept of SUPERIOR \& CONTACT (see examples in Schaub 1985: 159).

$$
\begin{array}{ll}
\text { Babungo, Niger-Kongo (Schaub 1985: 159) } \\
\text { superordinate (SUPERIOR) } & \rightarrow \text { tó } \\
\text { subordinate (SUPERIOR \& EXT }{ }^{\mathrm{C}} \text { ) } & \rightarrow \text { fúu } \\
\text { subordinate (SUPERIOR \& } \neg \mathrm{EXT}^{\mathrm{C}} \text { ) } & \rightarrow-
\end{array}
$$

The alternative mixed system is attested in Evenki (cf. Nedjalkov 1997: 74), where a postposition is used for the superordinate and another one for the subordinate concept of SUPERIOR \& NON-CONTACT.

$$
\begin{array}{ll}
\text { Evenki, Altaic (Nedjalkov 1997: 74) } & \\
\text { superordinate (SUPERIOR) } & \rightarrow \text {-ojo } \\
\text { subordinate (SUPERIOR \& EXT }{ }^{\mathrm{C}} \text { ) } & \rightarrow- \\
\text { subordinate (SUPERIOR \& } \neg \mathrm{EXT}^{\mathrm{C}} \text { ) } \rightarrow-\text { ugi }
\end{array}
$$

The characteristic of this language type with respect to the interaction between semantic categorizations and encoding strategy is that the elements denoting concepts in the domain of SUPERIOR are organized as an entailment scale (cf. Levinson 2000: 79). In our language sample, the language representing this language type is Nanafwe which expresses unspecified SUPERIOR and SUPERIOR \& NON-CONTACT. These concepts build an entailment scale of the form:

$$
<\text { SUPERIOR \& NON-CONTACT, SUPERIOR }>
$$

where the concept on the right entails the concept on the left. Entailment scales allow for a particular type of conversational implicatures: "assertion of a lower ranking (rightwards) alternate implicates that the speaker is not in a position to assert a higher ranking one" (cf. Levinson 2000: 79). By using a weaker expression, namely the superordinate concept, the hearer assumes that the speaker is not in a position to make a strong assertion by means of the subordinate concept.

The application of this inference is exemplified by the data in Nanafwe. In Game 5, the concept of NON-CONTACT has to be asserted. However, both expressions in (35) and (36) are judged as "possible" for the description of the highlighted situation. Although both assertions qualify as true 
for this situation, the explicit mention of SUPERIOR \& NON-CONTACT in (36) is judged as preferable since (35) generates a strong inference that the speaker does not have enough evidence to make explicit the concept of NON-CONTACT. The inverse discourse situation is tested in Game 2, in which the concept of CONTACT has to be asserted. In this context, (36) is false, and (35) may be successfully used since it implies CONTACT in that it does not assert NON-CONTACT.

j̀ lè bùzí-n nú táblí-n sú

SBJ:3.SG have candle-DEF in table-DEF on/above

'He holds the candle on/above the table.'

(Game 5: "true but not felicitous"; Game 2: "felicitous")

$$
\text { j̀ lè bùzín nú táblín sú_nglō }
$$

SBJ:3.SG have candle-DEF in table-DEF above

'He holds the candle above the table.'

(Game 5: "preferable"; Game 2: "false")

The encoding strategy of Nanafwe in Game 2 is represented in (37). The assertion of the superordinate concept is felicitous, since the subordinate concept is pragmatically inferred on the basis of the entailment scale in (34).

Game 2:

$$
\exists x \exists y
$$

highlighted picture: $\quad\left[\operatorname{LOC}\left(\mathrm{x},\left[\operatorname{SUPERIOR}(\mathrm{y}) \& \operatorname{EXT}^{\mathrm{C}}(\mathrm{y})\right]\right) \&\right.$

background picture: $\left.\neg \operatorname{LOC}\left(\mathrm{x},\left[\operatorname{SUPERIOR}(\mathrm{y}) \& \neg \mathrm{EXT}^{\mathrm{C}}(\mathrm{y})\right]\right)\right]$

semantics of Nanafwe sú:

$$
\lambda x \lambda y \operatorname{LOC}(x, \operatorname{SUPERIOR}(\mathrm{y}))
$$

pragmatic inference on the basis of (34):

$$
\begin{aligned}
& \operatorname{LOC}(x, \operatorname{SUPERIOR}(y)) \\
& +>\operatorname{LOC}\left(\mathrm{x},\left[\operatorname{SUPERIOR}(\mathrm{y}) \& \operatorname{EXT}^{\mathrm{C}}(\mathrm{y})\right]\right)
\end{aligned}
$$

Like the superordinate encoding languages, Nanafwe uses expressions that are not specified for CONTACT when this concept has to be asserted. In Game 1, 'a bird sitting on an elephant' is contrasted to 'a bird flying above an elephant'. The Nanafwe expression in (38) is a felicitous expression in this discourse situation, which according to (37) and (34) allows for two pragmatic inferences: the inference on the basis of the entailment scale in (34) and the inference from the asserted posture SIT to the concept of CONTACT as exemplified for superordinate encoding languages in Section 3. 
(38)

$$
\begin{array}{lll}
\text { ánúmān-n } \quad \text { tì swí-n sú. } & \\
\text { bird-DEF sit } & \text { elephant-DEF } & \text { on/above } \\
\text { 'The bird sits on/above the elephant.' (Game 1) }
\end{array}
$$

The inferential basis of the utterance in (38) is shown through the results in Game 11, in which the bird is sitting on a tree branch above the elephant. In this context, (38) has been judged as "true" but "confusing". The preferred expression is the utterance in (39).

$$
\begin{aligned}
& \text { ánúmān-n tì swí-n sú_nglō. } \\
& \text { bird-DEF sit elephant-DEF above } \\
& \text { 'The bird sits on/above the elephant.' (Game 11) }
\end{aligned}
$$

\section{Split systems}

Splitting introduces a further typological parameter that allows for multiple typological classifications of languages with respect to their superordinate/subordinate/mixed encoding properties in different constructions. A split system conditioned by semantic parameters is related to the opposition between static location and motion: Rapanui (Polynesian; Du Feu 1996: 126127) distinguishes between CONTACT and NON-CONTACT in static events, but neutralizes the opposition in motion events (see (36)). A further example is German: the distinction between CONTACT and NONCONTACT is neutralized in perlative situations (cf. ein Vogel fliegt über die Brücke 'a bird flies over the bridge', vs. ein Mann geht über die Brücke 'a man goes over the bridge').

(40) Rapanui, Polynesian (Du Feu 1996: 126-127)

$$
\begin{array}{llll}
\text { superordinate (SUPERIOR) } & \rightarrow & - & \text { i ruja } \\
\text { subordinate }\left(\text { SUPERIOR \& EXT }{ }^{\mathrm{C}}\right. \text { ) } & \rightarrow \text { a ruja } & - \\
\text { subordinate }\left(\text { SUPERIOR \& } \neg \mathrm{EXT}^{\mathrm{C}}\right. \text { ) } & \rightarrow \text { i ruja } & -
\end{array}
$$

A split system conditioned by syntactic parameters occurs in Modern Greek, which distinguishes between the subordinate concepts in prepositional constructions, but encodes only the superordinate concept in adverbial constructions. The Modern Greek prepositions are complex elements formed by the spatial adverb páno 'up' and the simple prepositions se 'LOC' and apó 'ABL' (cf. Theophanopoulou-Kontou 1993). ${ }^{10}$ 
(41) Modern Greek

$$
\begin{array}{llll}
\text { Modern Greek } & & \text { preposition } & \text { adverb } \\
\text { superordinate (SUPERIOR) } & \rightarrow & - & \text { páno } \\
\text { subordinate (SUPERIOR \& } \mathrm{EXT}^{\mathrm{C}} \text { ) } & \rightarrow \text { páno se } & - \\
\text { subordinate (SUPERIOR \& } \neg \mathrm{EXT}^{\mathrm{C}} \text { ) } & \rightarrow \text { páno apó } & -
\end{array}
$$

The point at issue in languages with syntactic splits is that the relevant concept for a discourse situation may motivate the choice of syntactic structure. In discourse situations that profile the subordinate concepts such as Games 3 and 6, a prepositional expression is needed to give an unambiguous description of the relevant situation (see Examples (42)-(43)).

$$
\begin{aligned}
& \text { to iðio katsaróli ine } \\
& \text { DEF:NOM.SG.N same:NOM.SG.N stove.pot:NOM.SG.N be:3.SG } \\
& \text { páno s-ti fotiá } \\
& \text { up__ LOC(=on)-DEF:ACC.SG.F fire:ACC.SG.F }
\end{aligned}
$$

'The same pot is on the fire.' (Game 3)

$$
\begin{aligned}
& \text { to tsukáli } \quad \text { ine } \\
& \text { DEF:NOM.SG.N fire.pot:NOM.SG.N be:3.SG } \\
& \text { páno apó } \quad t i \quad \text { fotiá } \\
& \text { up_ ABL(=above) DEF:ACC.SG.F fire:ACC.SG.F }
\end{aligned}
$$

'The fire-pot is above the fire.' (Game 6)

In discourse situations that profile the superordinate concept, such as in Game 9, the use of adverbial constructions is also possible (see Example (44)). The use of the preposition apó 'ABL' in front of the adverb does not form a complex preposition as in (43). The preposition in this example governs the adverb and its ablative function is interpreted as a static orientation (lit. 'in a directed axis falling from the upper region') and is not sensitive for the distinction between CONTACT and NON-CONTACT. The utterance in Example (44) may not be successfully used in the Games 3 or 6, in which the subordinate concepts need to be asserted.

$$
\begin{array}{lll}
i & \text { ikóna } & \multicolumn{2}{c}{\text { díxni }} \\
\text { DEF:NOM.SG.F picture:NOM.SG.F show:3.SG } \\
t i \quad \text { fotiá } & k e \text { to } \\
\text { DEF:ACC.SG.F fire:ACC.SG.F } & \text { and } & \text { DEF:ACC.SG.N }
\end{array}
$$


tsukáli apó páno
pot:ACC.SG.N ABL up

'The picture shows the fire and the pot upon/above it.' (Game 9)

The choice of an adverbial or a prepositional constructions is properly conditioned by the inferability of the landmark. If the landmark is uniquely inferable from the context, an adverbial construction may be chosen. The split system in encoding spatial regions adds a further parameter in the choice of syntactic construction: if the subordinate concept is relevant for the discourse situation, the prepositional construction must be used. The encoding strategy in Modern Greek is represented in (45)-(46). If the concept of CONTACT is relevant for the discourse situation, then it is a prepositional construction that is appropriate. If CONTACT is not relevant, then it is possible to use an adverbial construction that only encodes the superordinate concept of SUPERIOR. The argument of the concept of SUPERIOR in the adverbial construction is a free parameter that has to be filled in the context.

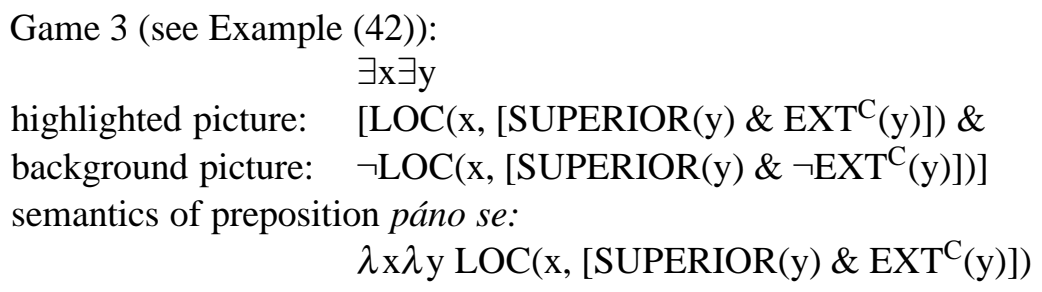

(46) Game 9 (see Example (44)):

$$
\exists \mathrm{x} \exists \mathrm{y}
$$

highlighted picture: $\quad\left[\mathrm{LOC}\left(\mathrm{x},\left[\operatorname{SUPERIOR}(\mathrm{y}) \& \neg \mathrm{EXT}^{\mathrm{C}}(\mathrm{y})\right]\right) \&\right.$

background picture: $\neg \operatorname{LOC}(\mathrm{x}, \neg \operatorname{SUPERIOR}(\mathrm{y}))]$

semantics of adverb páno:

$$
\lambda \mathrm{x} \operatorname{LOC}(\mathrm{x}, \operatorname{SUPERIOR}(\mathrm{y}))
$$

\section{Conclusions}

It has been shown that four possible language types may be distinguished with respect to the encoding of the superordinate concept of SUPERIOR and the subordinate concepts of SUPERIOR \& CONTACT and of SUPERIOR \& NON-CONTACT: (a) languages that only encode the superordinate con- 
cept; (b) languages that only encode the subordinate concepts; (c) languages that encode the superordinate concept and one of the subordinate concepts; and (d) languages with split systems that display the properties of one language type in one construction and the properties of another type in another construction. Speakers of representative languages of these four types have participated in a production experiment which was designed to reveal the encoding strategies that speakers with different semantic classifications use to resolve identical tasks. On this empirical basis, it has been shown that the possible language types with respect to the available semantic categorizations within a taxonomy of concepts crucially differ in the encoding strategies they use, depending on which concept is relevant in the discourse situation.

Languages that encode the subordinate concepts of this domain, namely SUPERIOR \& CONTACT and SUPERIOR \& NON-CONTACT, were shown to be characterized by obligatorily encoding the concept of CONTACT, i.e. irrespective of its relevance for the discourse situation.

Languages that encode the superordinate concept were shown to ignore the concepts of CONTACT/NON-CONTACT whenever they are not relevant for the discourse situation. In the case that these concepts are needed in order to perform the communicative task, languages of this type were shown to make use of three different means of conveying this information: (a) they make use of a different lexicalization pattern, e.g. subordinate verbs in Korean, giving the same semantic representation by alternative means; (b) they encode alternative concepts implied by the concepts of CONTACT/NONCONTACT to describe the same situation, e.g. Yucatec Maya speakers used the concept of position in the absolute frame of reference (HIGH) in order to describe the situation of NON-CONTACT; or (c) they make use of different concepts, that allow for inferences about the concepts of CONTACT/NONCONTACT, e.g. Yucatec Maya speakers used the posture SQUAT that allows for the pragmatic inference of CONTACT.

Languages of the mixed type display a semantic classification involving one subordinate concept and the superordinate one. Concerning the impact of semantic classifications to encoding strategy, these languages provide a particular inferential means for the conveyance of the subordinate concepts, namely implicatures based upon the entailment scale formed by the abstract superordinate concept and the available subordinate one. This language type was represented in our sample by Nanafwe that displays a postposition encoding the superordinate concept and a postposition encoding SUPERIOR $\&$ NON-CONTACT. The use of the superordinate concept in this language 
allows for inferences that the NON-CONTACT is excluded, since it is not explicitly mentioned.

Some languages were shown to display constructional splits with respect to the encoding of SUPERIOR: the point at issue in the case of split systems is that the relevance of CONTACT/NON-CONTACT for the discourse situation can motivate the choice of construction. For instance, the condition that properly accounts for the choice between an adverbial and a prepositional construction is the inferability of the landmark: the adverbial construction is possible when the landmark is retrievable from the context. In a language with a split system in encoding spatial regions, the relevance of a certain spatial region may influence the syntactic choice as well. Modern Greek has been shown to display such a constructional split: the prepositional paradigm encodes the distinction of the subordinate concepts, whereas the adverbial paradigm only encodes the superordinate concept. Thus, in conditions in which the subordinate concept has to be asserted, the adverbial construction is not felicitous, even if the landmark is inferable from the context. This construction is only possible when the superordinate concept is at issue.

Finally, a comment on the ontology dealt with in this article is necessary here, especially with respect to the dimension of objectivity in typological perspective (Nickles et al., this vol.). The introduced concepts are treated as a minimal requirement in order to give an adequate account about the differences between the object languages. Not all languages encode these concepts, but encoding is not the only way for a concept to get a place in grammar. As the discourse patterns in each language type show, the same conceptual relation serves as resource for making inferences and as basis for solving communicative tasks across languages.

\section{Notes}

1. Cordial thanks to Amani Bohoussou, Marija Maya Brala, Sonia Cristofaro, Silke Fliess, Dagmar Haumann, Robin Hörnig, Johannes Helmbrecht, Christian Lehmann, Silvia Luraghi, Daniela Nienstedt, Yoko Nishina, Su-Rin Ryu, Maria Sepsa, Alkistis Skopetea, Olga Stralets, Irina Utjuznikova, Elisabeth Verhoeven, and Thomas Weskott who have contributed to this paper as language and/or linguistics experts.

2. The highlighted pictures 11-13 are designed to be compared with the descriptions for the highlighted pictures 1-3: 11-13 differ to 1-3 with respect to the concept of CONTACT, but - in contrast to pictures 1-3 - they display the same POSTURE.

3. Many languages, e.g., specify properties of the landmark, e.g. localization on a surface or not in Koromfe (Rennison 1997: 175-178), localization on top of a tall object vs. on the 


\section{Stavros Skopeteas}

flat surface of an object vs. on a surface, that is conceived as the outside of an object, in Wari (cf. Everett and Kern 1997: 265).

4. See for instance the concept of SUPPORT for the French preposition sur in Vandeloise (1986: 195), the concept of STABILIZATION for the French preposition sur in Aurnague and Vieu (1993: 421), or the functional properties of the English preposition above in Carlson (2000: 100).

5. Glosses: $1=1$ st person; $3=3$ rd person; $\mathrm{ABL}=$ ablative; $\mathrm{ACC}=$ accusative; $\mathrm{CL}=$ classifier; $\mathrm{CON}=$ converb; $\mathrm{D}=$ deictic; $\mathrm{DECL}=$ declarative; $\mathrm{DEF}=$ definite; EXIST=existential; $\mathrm{F}=$ feminine; FACT=factitive; GEN=genitive; HESIT=hesitative; INAN=inanimate; INF=infinitive; INSTR=instrumental; LOC=locative; $\mathrm{M}=$ masculine; $\mathrm{N}=$ neuter; $\mathrm{NOM}=$ nominative; $\mathrm{NR}=$ nominalizer; PASS=passive; POS=positional; $\mathrm{PFV}=$ perfective; $\mathrm{PL}=$ plural; $\mathrm{PRES}=$ present; $\mathrm{SBJ}=$ subject; $\mathrm{SG}=$ singular; $\mathrm{TOP}=$ topic.

6. Cf. Talmy (2000; Vol. II, 21-146) on lexicalization patterns; see also Lehmann (1992) on central/decentral encoding of spatial functions.

7. Cf. Levinson (1996) on relative vs. absolute spatial regions; a further possibility would be a 'deictic solution': the location of a localized object in space is specified with respect to the perspective of the speaker (i.e. higher vs. lower than the speaker). Such a system is reported for Palestinian Arabic (cf. Regier 1991).

8. Cf. Stolz 1996: §6.5.3: $\mathrm{ka}$ 'nal = "location on the major orientational plane or axis of VERT or OBS, location is further away from the zero point of the axial system"; kàabal = "location on the major orientational plane or axis of VERT or OBS, location is closer to the zero point of the axial system."

9. The postposition sú_nglō is formed on the basis of the postposition sú. The etymology and compositional meaning of the suffix -nglō is unclear.

10. Both simple prepositions combine with different spatial adverbs giving rise to different semantic distinctions. Complex prepositions with se 'LOC' are only used in static and allative relations, whereas complex prepositions with apó 'ABL' are used in static, allative, ablative, and perlative relations. Thus, there is an opposition between complex prepositions with se 'LOC' and apó 'ABL' in static and allative relations, which renders different distinctions in different spatial regions. In combination with the adverb mésa 'inside', the complex preposition mésa se encodes a location in the interior of a bounded entity and the complex preposition mésa apó encodes a location in the inner side of a boundary. In combination with the adverb brostá 'in front', the complex preposition brostá se encodes a location in a place that is contiguous to the front side of the landmark and the complex preposition brostá apó encodes a location in a place which may be anywhere in the front axis of the landmark. In combination with the adverb páno 'up', the opposition between the two complex prepositions encodes the opposition between the concepts of CONTACT and NON-CONTACT. A compositional account for the opposition between se and apó could be based on the concept of a BOUNDED REGION for the preposition se and UNBOUNDED REGION/DIRECTION for the preposition apó (see Tachibana 1994). These concepts only hold for the use of the simple prepositions in combination with spatial adverbs and for their opposition in static and allative relations. In the glosses of this paper, the prepositions se and apó are glossed with their meanings as free morphemes and the meaning of the complex preposition is given non-compositionally in parenthesis. 


\section{References}

Aurnague, Michel, and Laura Vieu

1993 A three-level approach to the semantics of space. In The Semantics of Prepositions, Cornelia Zelinsky-Wibbelt (ed.), 393-439. Berlin, New York: de Gruyter.

Brala, Marija M.

this vol. Spatial 'on' - 'in' categories and their prepositional codings across languages. Universal constraints on language specificity.

Carlson, Laura A.

2000 Object use and object location: the effect of function on spatial relations. In Cognitive Interfaces: Constraints on Linking Cognitive Information, Emile van der Zee and Nikanne Urpo (eds.), 94-115. Oxford: Oxford University Press.

Cole, Peter

1985 Imbabura Quechua. London etc.: Croom Helm.

$\mathrm{Du}$ Feu, Veronica

1996 Rapanui. London, New York: Routledge.

Enfield, Nick J.

2002 Semantics and combinatorics of 'sit', 'stand', and 'lie' in Lao. In Newman (ed.), 25-41.

Everett, Daniel L., and Barbara Kern

1997 Wari: The Pacaas Novos Language of Western Brazil. London, New York: Routledge.

Klein, TODO

1991 TODO: REFERENCE MISSING.

Kornfilt, Jaklin

1997 Turkish. London, New York: Routledge.

Lehmann, Christian

1992 Yukatekische lokale Relatoren in typologischer Perspektive. Zeitschrift für Phonetik, Sprachwissenschaft und Kommunikationsforschung 45: 626-641.

Levinson, Stephen

1996 Language and space. Annual Review of Anthropology 25: 353-382.

2000 Presumptive Meanings: The Theory of Generalized Conversational Implicature. Cambridge/Mass.: MIT Press.

Macaulay, Monica

1996 A Grammar of Chacaltongo Mixtec. Berkeley, etc.: University of California Press.

Nedjalkov, Igor

1997 Evenki. London, New York: Routledge.

Newman, John

2002 A cross-linguistic overview of the posture verbs 'sit', 'stand', and 'lie'. In Newman (ed.), 1-24.

Newman, John (ed.)

2002 The Linguistics of Sitting, Standing, and Lying. Amsterdam, Philadelphia: Benjamins. 


\section{Stavros Skopeteas}

Nickles, Matthias, Adam Pease, Andrea C. Schalley, and Dietmar Zaefferer this vol. Ontologies across disciplines.

Regier, Terry

$1991 \quad$ Learning spatial concepts using a partially-structured connectionist architecture. International Computer Science Institute (Berkeley) Technical Report 91-050.

Rennison, John R.

$1997 \quad$ Koromfe. London, New York: Routledge.

Schalley, Andrea C., and Dietmar Zaefferer

this vol. Ontolinguistics - an outline.

Schaub, Willi

1985 Babungo. London, etc.: Croom Helm.

Stolz, Christel

1996 Spatial Dimensions and Orientation of Objects in Yucatec Maya. (BochumEssener Beiträge zur Sprachwandelforschung 29). Bochum: Brockmeyer.

Tachibana, Takashi

1994 Spatial expressions in Modern Greek. Studies in Greek Linguistics 14: 525539.

Talmy, Leonard

2000 Toward a Cognitive Semantics. Volume I: Concept Structuring Systems. Volume II: Typology and Process in Concept Structuring. Cambridge/MA., London: MIT Press.

Theophanopoulou-Kontou, Dimitra

1993 The complex Modern Greek prepositions and their structure [I sinthetes prothesis tis Neas Ellinikis ke i domi tus]. Studies in Greek Linguistics 13:311-331.

Wunderlich, Dieter, and Michael Herweg

$1991 \quad$ Lokale und Direktionale. In Semantik: Ein internationales Handbuch der zeitgenössischen Forschung, Arnim von Stechow and Dieter Wunderlich (eds.), 758-785. Berlin, New York: de Gruyter. 